\title{
Automation of Drawbridge Model using by PLC
}

\author{
Satyendra Pratap Singh ${ }^{1}$, Rishi Kumar Anand ${ }^{2}$, Vibhanshu Vinay ${ }^{3}$, Shubham Srivastava ${ }^{4}$, Sachin Kumar ${ }^{5}$, \\ Prof. Anuja Shaktawat ${ }^{6}$ \\ B.Tech, Electrical and Electronics ( $4^{\text {th }}$ year), IMS Engineering College, Ghaziabad, Uttar Pradesh, India ${ }^{1,2,3,4,5}$ \\ Asst. Prof, IMS Engineering College, Ghaziabad, Uttar Pradesh, India ${ }^{6}$
}

\begin{abstract}
An automatic or movable bridge is a special type of bridge that moves to allow passage (usually) for boats or large ships. In this project automatic bridge is fully automated by using PLC. Automatic bridge is operated in countries like United Kingdom, United States of America and Howrah Bridge in India. The main objective of this project is to allow passage to huge gigantic cargo ships on the canals or lagoons because for them bridge can't be build because of their shape and size. The idea is to automate the process of ship detection, opening or closing of a bridge, controlling the signals and road barriers. The purpose of the research is to replace the manual system which is currently used. The ABB PLC is used to mechanize the system. Sensors such as Proximity are used to provide input to the system. And motor such as servo and DC motor serves as an output. Ladder diagram as a programming language is used to control the whole system between the input and output. With the help of Ultrasonic sensor, Proximity sensor the arrival and leaving of the system is Monitored and bridge is operated accordingly.
\end{abstract}

Keywords: PLC, Drawbridge Modal, Proximity Sensor, Ladder Logic.

\section{I.INTRODUCTION}

A bridge over a navigable waterway must allow boats and ships to cross its path, usually by being tall enough to allow them to sail underneath it. Sometimes it is impractical to build a bridge high enough; for example, it may rise too steeply or block the view of an important landmark. In such cases, the bridge can be designed so it can be easily moved out of the way for vessels that are too large to sail under it. The type of movable bridge that most people think of as a draw bridge is similar to those that spanned medieval castle moats.

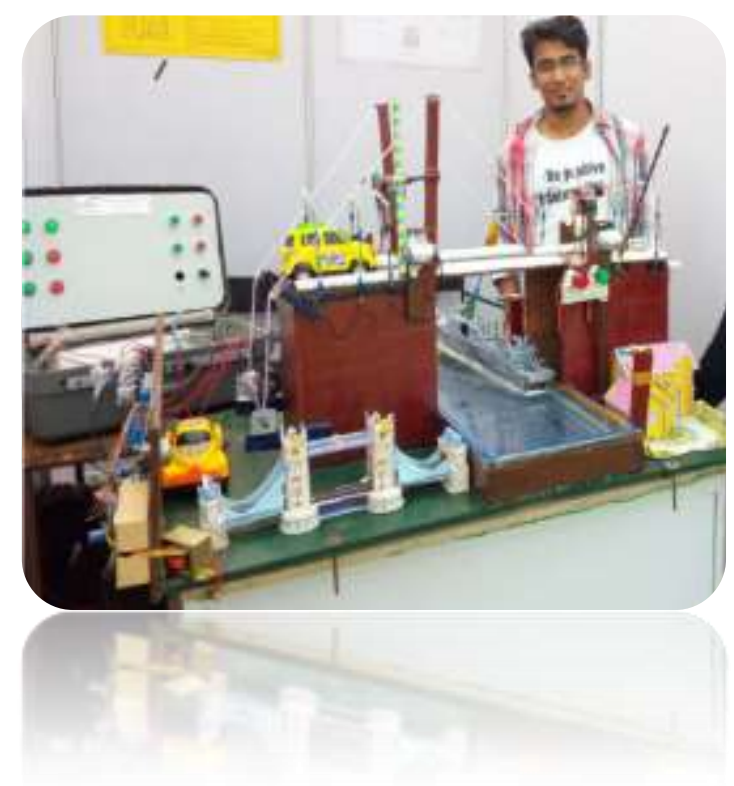

Technically called "bascule bridges" from the French word for seesaw, they may open at one end and lift to one side (single leaf) or open in the middle and lift to both sides (double leaf). Another common type of movable bridge is the vertical lift span, in which the movable section is supported at both ends and is raised vertically like an elevator. Retractable bridges are made so the movable span slides back underneath an adjacent section of the bridge. Swing bridges are supported on vertical pivots, and the movable span rotates horizontally to open the bridge. Movable bridges are relatively rare because they are more expensive to operate and maintain than stationary bridges. They also impede traffic - on the water when they are closed and on the roadway or rail line when they are open.(2) 
Programmable Logic Controllers (PLCs), also referred to as programmable controllers, are in the computer family. They are used in commercial and industrial applications. A PLC monitors inputs, makes decisions based on its program, and controls outputs to automate a process or machine. Various types of PLCs by various companies are available today like Siemens; ABB etc. (1) The Automatic Bridge Control System consists of three important parts. The first part is the PLC controller and second part is hardware. These usually comprise of prototype model of bridge. The third part is the sensor. The sensor checks the presence of Ship. (1)

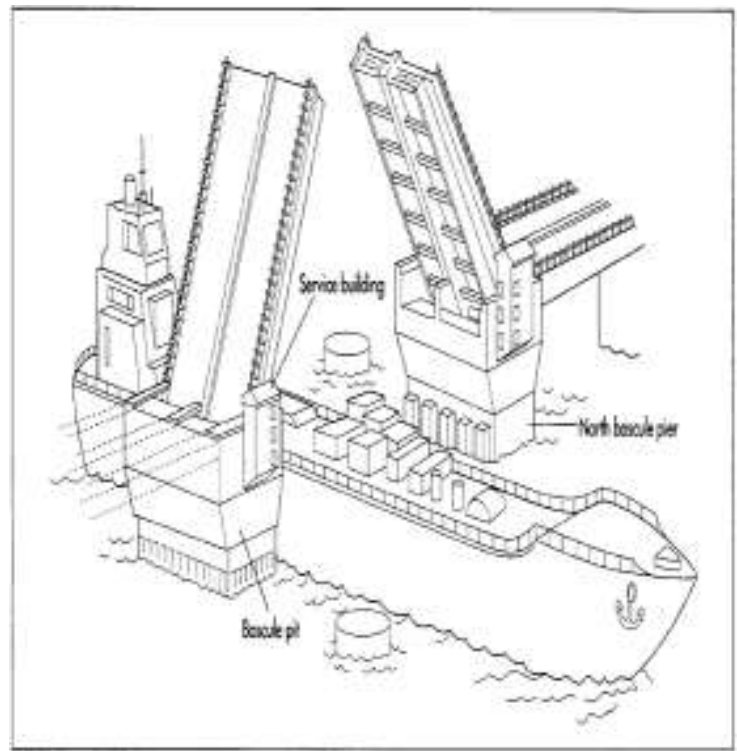

Fig 1- A Typical Draw- Bridge. (3)

This project is to design and construct a DRAWBRIDGE using a programmable logic controller. Proximity sensor is used to know the ship position. . PLC (ABB) PM 554 ETH is used for this purpose. Ship is detected by Proximity sensor which is placed at certain distance from the bridge. Sensor output provides input to the PLC and it'll drive DC motor, Servo motor and Signal Poles according to programming.

\section{II.LITERATURE REVIEW}

Muhammad Arshad Khattak et al expressed his idea related to interfacing of Sensor with PLC in one of his paper. The main object of their paper was to design and simulate an intelligent traffic control system. The system developed is able to detect the presence or absence of vehicles within certain range by setting the appropriate duration for the traffic signals to react accordingly. By employing mathematical functions to calculate the appropriate timing for the green signal to on, the system can help to solve the problem of traffic congestion. Hardware simulation tests were successfully performed on the algorithm implemented into a PLC [4].

\section{i. Design}

Each draw bridge is a unique structure designed for its particular location and traffic needs. There are at least half a dozen different design concepts, but the most common is the bascule type. In double-leaf or four-leaf (a double-leaf bridge with separate leaves for each direction of vehicular traffic) bascule bridges, each leaf can be raised and lowered independently. The energy required rising and lower the bascule leaves is greatly reduced by counterbalancing each leaf with a compact weight on the opposite side of the pivot axle (turn-on). In various bascule designs, this counterweight might be located above the roadway and allowed to pivot below the roadway as the bridge is raised, or it might be located below the roadway and allowed to descend into a basement level (often well below the waterline) as the bridge opens. It might be located adjacent to the turn-on or, for greater leverage, be set back a few yards (meters). As an example, each pair of 500-ton (450-metric-ton) leaves on the Casco Bay Bridge is balanced with an 800-ton (720-metric-ton) counterweight. The lift mechanism is usually a rack-and-pinion gear arrangement driven by electric motors [2].

\section{ii. Description of PLC}

The first Programmable Logic Controller, PLC was developed by a group of engineers at General Motors in 1968. It was developed when that company was looking for an alternative to replace complex relay control system. The term 'programmable logic controller' is defined by EN 61131-1 as a digitally operating electronic system which uses a 
programmable memory for the internal storage of user-oriented instructions for implementing specific functions such as logic, sequencing, timing, counting and arithmetic to control through digital or analogue inputs and outputs, various machines or process[5].

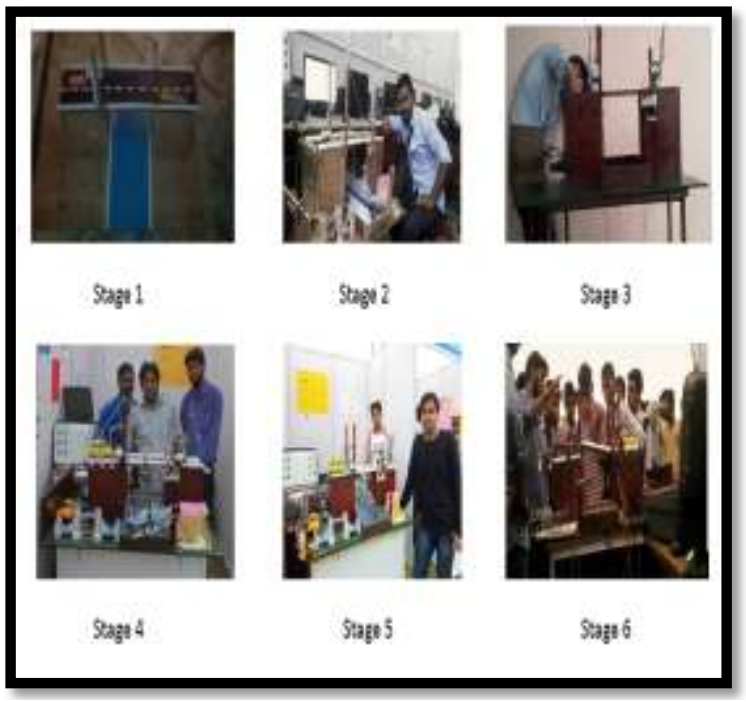

\section{Ladder Programming algorithm -}

There are many types of programming languages in Programmable Logic Controller, PLC. Languages are typically fixed to Ladder Logic (LD), Sequential Function Block (SFC), Function Block Diagram (FBD) and Structure Text (ST). The common program language of PLC is ladder diagram [5].

\section{Ladder Logic}

Ladder diagram is an automatic control diagram language that developed during World War II.

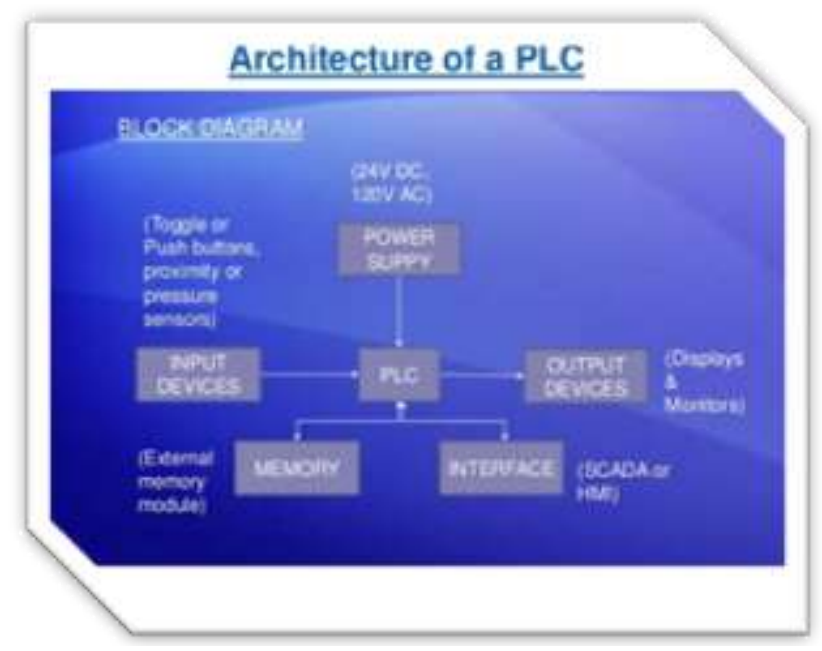

Ladder logic is the Primary programming language of programmable logic controllers. Since the PLC was developed to replace relay logic control systems, it was only natural that the initial language closely resembles the diagrams used to document the relay logic. By using this approach, the engineers and technicians using the early PLCs did not need retraining to understand the program. To introduce ladder logic programming simple switch circuits are converted to relay logic and then to PLC ladder logic. Any control task modifications are done by changing the program. This is why the use of the PLC is preferred to the traditional hard wired circuits in industrial controls [5].

\section{iii. Interfacing of PLC}

The interface card is used between the sensors output and PLC for interfacing purpose. In this system card used is opto coupler. When the input is detected by the sensor then a current limiting resistor is used for reducing the current and drops the voltage for a certain limit. When sensors provide output then a resistor is used in series with the opto-coupler [4]. 


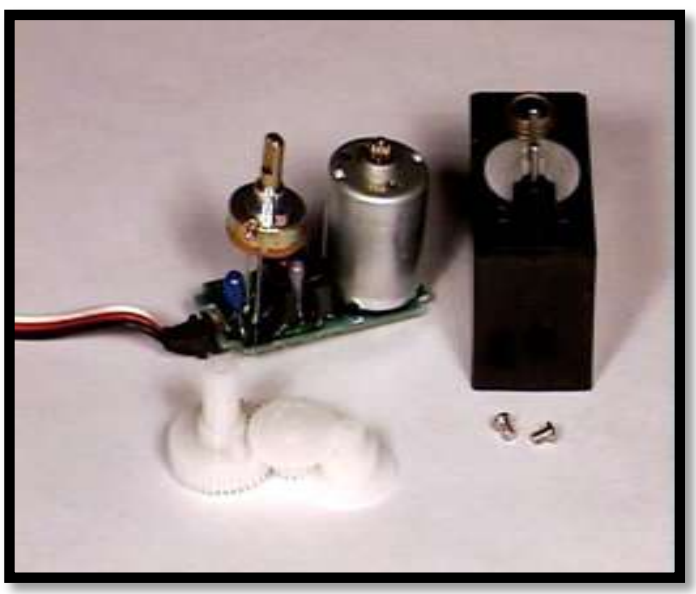

Figure 2 Servo Component

Acy M. Kottalil et al in his Paper automatic railway gate control shows a procedure to open and close the railway crossing according to condition of the sensors which sense presence or absence of train. The main objective of this paper is to provide an automatic railway gate at a railway crossing replacing the gates operated by the gatekeeper [6]. These types of gates can be employed in an unmanned level crossing where the probability of accidents is higher and reliable and flexible operation is required. Since, the operation is automatic; error due to manual operation is prevented with the help of Proximity sensors .The arrival and leaving of the train is monitored and the gate is operated accordingly. For controlling the Gate servo motor is used. A servo is a mechanical motorized device that can be instructed to move the output shaft attached to a servo wheel or arm to a specific position. Inside the servo box there is a dc motor mechanically linked to a position feedback potentiometer, gearbox, electronic feedback control loop circuitry and a motor drive electronic circuit as shown in fig. 2

Servos are controlled by sending them a pulse of variable width. The control wire is used to send this pulse which controls the movement of a motor. It is important to note that different servo motor will have different constraints on their rotation but they all have a neutral position, and that position is always approximately around 1.5 milliseconds. The angle is determined by the duration of a pulse that is given to the control wire [1].

When a pulse is given to a servo motor that is less than $1.5 \mathrm{~ms}$ then servo rotates to a position and holds its output shaft some number of degrees anti-clockwise from the neutral point. When the pulse is larger than $1.5 \mathrm{~ms}$ then opposite occurs. Generally the minimum pulse width will be approximately about $1 \mathrm{~m}$ wide and the maximum pulse width will be $2 \mathrm{~ms}$ wide. This way servo motor rotates maximum 180 degree. It does not rotate continuously [6]. This motor is best for our application to operate road barriers present on the either side of the bridge [1].

\section{III.SYSTEM COMPONENTS \& DESIGN}

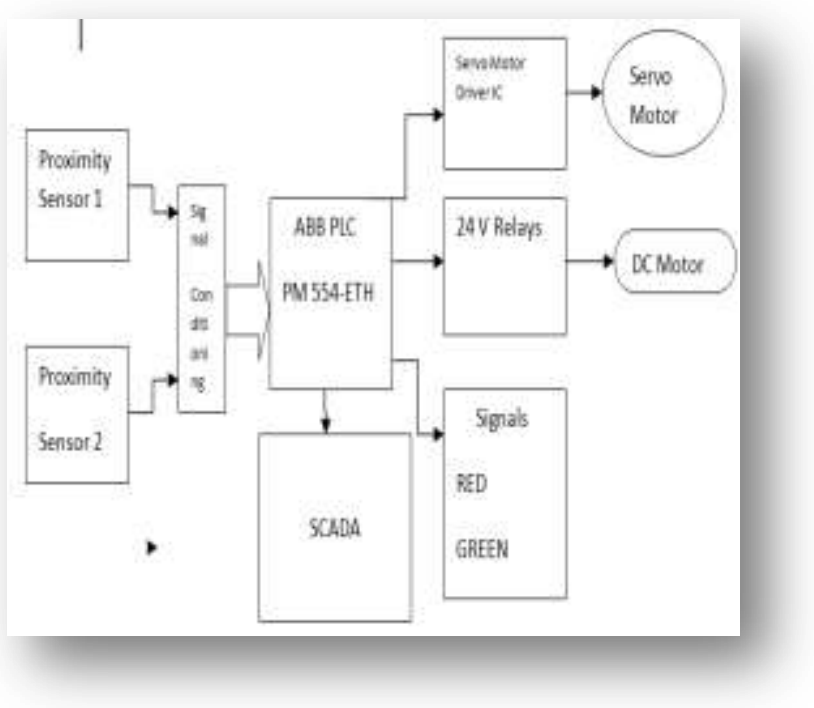

Fig 3 Block Diagram of System 
The system deals with controlling the process of opening and closing of bridge automatically with the help of PLC. The system is design by using sensors such as Proximity, Ultrasonic, DC motor \& Stepper motor.

\section{a. Proximity Sensor}

A proximity sensor is a sensor able to detect the presence of nearby objects without any physical contact. A proximity sensor often emits an electromagnetic field or a beam of electromagnetic radiation (infrared for instance), and looks for changes in the field or return signal. The object being sensed is often referred to as the proximity sensor's target. Different proximity sensor targets demand different sensors. For example, a capacitive or photoelectric sensor might be suitable for a plastic target; an inductive proximity sensor always requires a metal target. In this model two $24 \mathrm{~V}$ PNP proximity sensors are used for detecting arrival and leaving of ship.

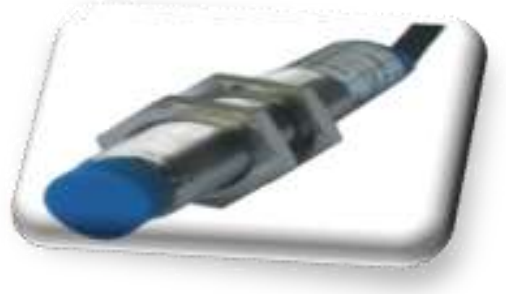

Figure 5 Proximity Sensor

\section{b. 24V Relay}

A relay is an electrically operated switch. Many relays use an electromagnet to mechanically operate a switch, but other operating principles are also used, such as solid-state relays. The first relays were used in long distance telegraph circuits as amplifiers: they repeated the signal coming in from one circuit and re-transmitted it on another circuit. Relays were used extensively in telephone exchanges and early computers to perform logical operations. In this project we are using six $24 \mathrm{~V}$ relays to perform our operation.

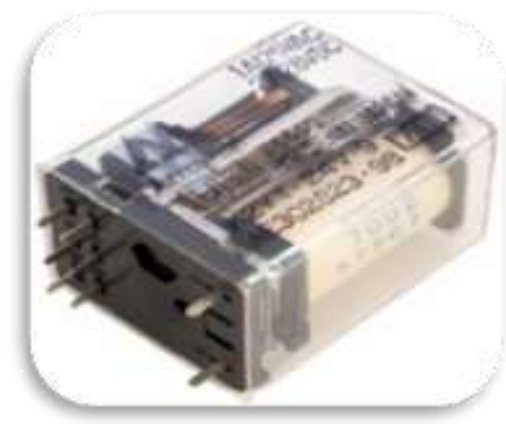

Figure 6 24V Relay

\section{c. Ultrasonic Sensor}

Ultrasonic Sensors are self-contained solid-state devices designed for non-contact sensing of solid and liquid objects. For many applications, such as monitoring the level of water in a tank, ultrasonic technology lets a single device to do a job that would otherwise require multiple sensors. The sensors are available in several sensing ranges and styles with either an analog or discrete output depending on the model. In this project two ultrasonic sensors along with their receivers are used to detect the traffic on the bridge.

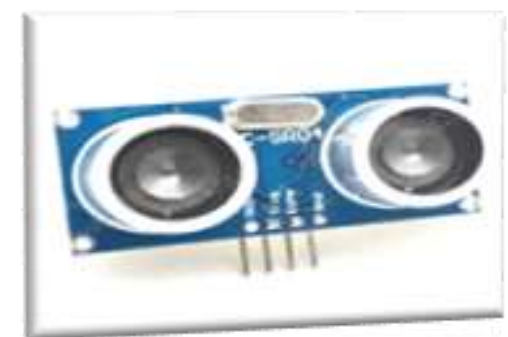




\section{d. 24V Power Supply}

A power supply is an electronic device that supplies electric energy to an electrical load. The primary function of a power supply is to convert one form of electrical energy to another. As a result, power supplies are sometimes referred to as electric power converters. Some power supplies are discrete, stand-alone devices, whereas others are built into larger devices along with their loads. In this project $24 \mathrm{~V}$ power supply is used for carrying out all the operations.

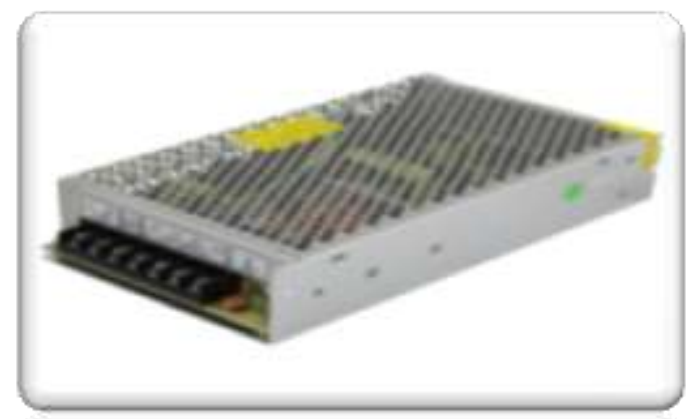

Figure 8 24V Power Supply

\section{e. DC Motor}

A DC motor is any of a class of rotary electrical machines that converts direct current electrical energy into mechanical energy. The most common types rely on the forces produced by magnetic fields. Nearly all types of DC motors have some internal mechanism, either electromechanical or electronic; to periodically change the direction of current flow in part of the motor. In this project two DC motor are used in the either side of the bridge for controlling the barricades present on the bridge for controlling the traffic when the ship arrives.

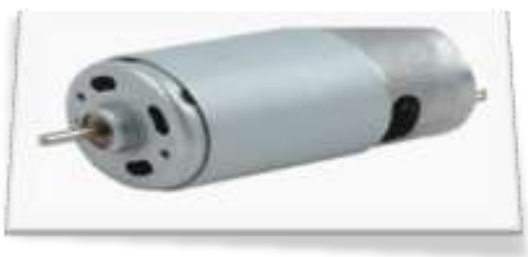

Figure 9 24V DC Motor

\section{f. Servo Motor}

Servo motor is used to opening and closing of bridge according to signal of proximity and ultrasonic sensor. Servo motor basically works on pulse of variable width. Generally the width of the pulse ranges from $1 \mathrm{~ms}$ to $2 \mathrm{~ms}$, hence servo motor rotates maximum up to $180^{\circ}$ and it cannot rotate continuously like DC motor [6].

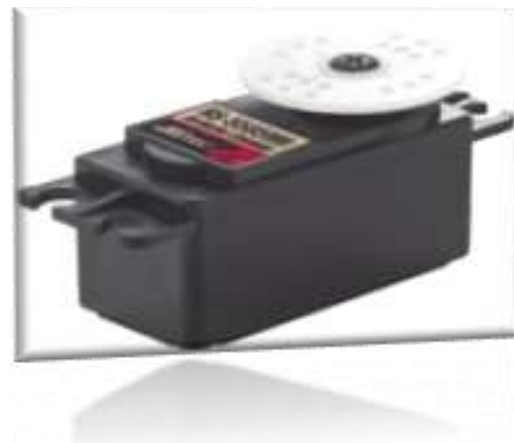

Figure 10 Servo Motor

\section{g. Signal Pole}

Signal pole is used to indicate vehicle to stop. When ship would be detected, red light would be ON to indicate vehicle to stop because bridge will be about to open and when will ship pass through bridge, so after that bridge is closed then Green lights is turned ON again. 
Vol. 4, Issue 5, May 2017

\section{IV.TRAFFIC CONTROL SYSTEM}

\section{A. Design}

Practically Inductive Loops are used as sensors to detect the presence of vehicles on intersections. Its basic function is to provide interrupts to controller unit. It has two parts, first is coil and second is the detector unit. Coil is a main part of a sensor and consists of one or more loops of wire embedded in the pavement [2].

This inductive coil is connected with the detector unit, which is an electronic circuit. When vehicles passes over or rests on the inductive loop then due to induction on vehicle more current flow through inductive loop and this change of current also changes frequency. Detector unit can detect these changes. Finally, detector unit sends an interrupt signal to controller unit [4].

\section{B. Hardware}

In prototype design Ultrasonic sensors are used, for prototype it is not possible to design an induction loop. As the basic function of induction loop in Intelligent Traffic Control System is used to provide an interrupt signal to controller unit. We use Ultrasonic sensors rather than induction loops. In our design, Ultrasonic sensors provide an interrupt signal to controller unit. In case when vehicle reaches in front of sensors, then it provides an interrupt [4].

\section{Outcomes of the Model}

This system is designed to control the process of opening and closing bridge automatically when ship will be detected. Ship would be detected by Proximity Sensors located at the either side of the bridge. When ship will be detected it sends high to low pulse to PLC via Signal-conditioning. As soon as PLC gets high to low signal it drives the DC to close road barriers and signal changes from green to red. Then after PLC drives Servo motor to open the bridge and it will continuously monitor the states of Proximity sensor. Proximity sensor is used to check the status of the bridge, whether bridge is open or not. As PLC gets signal from Proximity sensor it would stop Servo motor. Hence the bridge is opened. As soon as ship passes through the bridge it'll detect by sensor at other side of the bridge and it will send high to low signal to PLC. PLC first drives Servo motor in reverse direction until bridge is totally closed. Then road barrier will be opened and signal changes from red to green.

\section{V.CONCLUSION \& FUTURE SCOPE}

\section{1) Conclusion}

In this paper, we presented designing of a PLC based control system for automatic opening and closing of bridge. The automated process efficiently reduces the man power required for the process and also increases the efficiency. The use of PLC for controlling action of the system effectively leads to intelligent system which requires less time compared to human and this system also ensures safety

\section{2) Future Scope}

- SCADA (supervisory control and data acquisition) implementation can be done for monitoring all the process.

- CCTV camera can be utilized for more accuracy in the ship detection.

- This process can be implemented between twin cities divided by river, lagoons making it as effective measure of transport.

\section{ACKNOWLEDGMENT}

We are thankful to our Prof. Yashpal Singh of Rhythm Automation who supported us by providing us all the necessary equipments for our project and inspired us during this work. We are most thankful to our mentor Prof. Anuja Shaktawat for providing us valuable guidance during this project work without her valuable assistance and support the project would not have been a success. Special thanks to Dr. Rishi Asthana Head of Electrical\& Electronics Department to provide us all the necessary help from the department.

\section{REFERENCES}

1. Bhavin V. Mangukiya, Sandip B. Kheni, Kaushik B. Desai, Prof. Kaushika Patel, "Bridge Control Automation using PLC", IJSRD International Journal for Scientific Research \& Development| Vol. 4, Issue 02, 2016

2. http://www.madehow.com/Volume-6/Draw-Bridge.html

3. http://www.madehow.com/images/hpm_0000_0006_0_img0046.jpg

4. Muhammad Arshad Khattak, 'PLC based intelligent traffic control system', International Journal of Electrical \& Computer Sciences IJECSIJENS Vol: 11 No: 06

5. Sandar Htay, Su Su Yi Mon ,"Implementation of PLC Based Elevator Control System”, ISSN 2277-1956/V3N2-91-100

6. Acy M. Kottalil, Abhijith S, Ajmal M M, Abhilash L J.,Ajith Babu," Automatic railway gate control system.” International Journal of Advanced Research in Electrical, Electronics and Instrumentation Engineering, Vol. 3, Issue 2, February 2014. 


\section{BIOGRAPHIES}

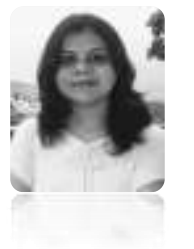

Prof. Anuja Shaktawat has completed her M.Tech from MANIT, Bhopal. She has also worked with Reliance Infrastructure Ltd and presently working as a professor in IMS Engineering College in Electrical \& Electronics Department.

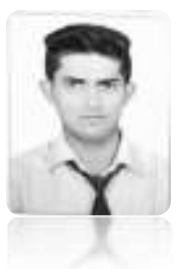

Satyendra Pratap Singh born in Allahabad (U.P), India on $13^{\text {th }}$ of August 1995. He has completed his school education from U.P board with $1^{\text {st }}$ div in Intermediate and presently pursuing his engineering in Electrical \& Electronics ( $4^{\text {th }}$ year) from Ghaziabad Uttar Pradesh India.

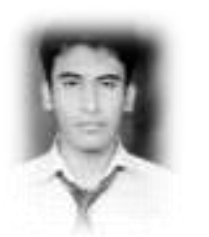

Vibhanshu Vinay born in Gorakhpur (U.P), India on 18th of August 1993. He has completed his school education from C.B.S.E board with 1 st div in Intermediate and presently pursuing his engineering in Electrical \& Electronics ( $4^{\text {th }}$ year) from Ghaziabad Uttar Pradesh India

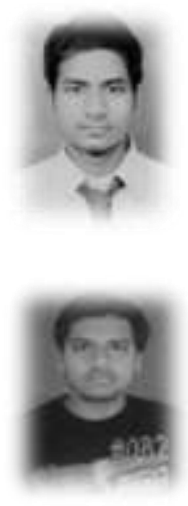

Rishi Kumar Anand born in Gorakhpur (U.P), India on 26th of April 1995. He has completed his school education from U.P board with 2 nd div in Intermediate and presently pursuing his engineering in Electrical \& Electronics ( $4^{\text {th }}$ year) from Ghaziabad Uttar Pradesh India.

Shubham Srivastava born in Varanasi (U.P), India on 22nd of June 1995. He has completed his school education from I.S.C board with first division in Intermediate and presently pursuing his engineering in Electrical \& Electronics $\left(4^{\text {th }}\right.$ year) from Ghaziabad Uttar Pradesh India.

Sachin Kumar born in Badaiu (U.P), India on $7^{\text {th }}$ of June 1996. He has completed his school education from U,P board with first division in Intermediate and presently pursuing his engineering in Electrical $\&$ Electronics $\left(4^{\text {th }}\right.$ year) from Ghaziabad Uttar Pradesh India 